\title{
The Impact Of Change-Oriented Leadership On Voice Behavior And Intent To Quit With Employee Personality As Moderator And Perceived Issue Threat As Mediator
}

\author{
Muna Ibrahim G. Alyusef \\ Huazhong University of Science \& Technology, Wuhan, Pr China \\ University of Hail, Kingdom Of Saudi Arabia \\ PengCheng Zhang \\ Pr China
}

doi: 10.19044/esj.2016.v12n2p109 URL:http://dx.doi.org/10.19044/esj.2016.v12n2p109

\begin{abstract}
Change-oriented leadership is a specific leadership style in encouraging employee voice behaviors. In present day, voice is regarded as an essential tool in improving the performance of any organization. Employee voice acts as a driving factor in influencing organizational change and suggesting innovative ideas. Employee personality moderates the relationship between change-oriented leadership and perceived issue threat. When employees feel they will not be treated unjustly and are free to express their ideas, they are more likely to voice their opinions without hindrance. Moreover, by anticipating positive responses from the manager, employees are more likely to have trust in management to appreciate their input; hence managerial openness is a positive indicator of voice behaviors and intent to quit. This study has four propositions. The first states that transformational leadership has a positive impact on voice behaviors and intent to quit. Secondly, managerial openness has a positive impact on voice behaviors and intent to quit. Thirdly, employee personality moderates this relationship while lastly; perceived issue threat mediates this relationship. The study concludes in the acceptance of these propositions. Researchers should explore the diversity factors associated with change-oriented leadership and voice behaviors.
\end{abstract}

Keywords: Change-oriented leadership, transformational leadership, managerial openness, intent to quit, voice behaviors, perceived issue threat, employee personality 


\section{Introduction}

Nowadays the hypercompetitive environment of the business world is driven by the suggestions and comments of employees aimed at improving organizational operations (Morrison \& Milliken, 2000). It is simply not possible for top management to figure out all the necessary initiatives (Senge, 1990). Voice denotes the expression of ideas and concepts either verbally or in writing that are concerned with job satisfaction or subsequent organizational problems, or the requirement to enhance workplace circumstances and personnel, team, departmental or organizational goals (Olson-Buchanan \& Boswell, 2002). For instance, Edmondson (2003) found that the ability of all individuals to give considerations and thoughts regarding basic work forms portrays effective learning in different sorts of groups. However, in spite of this "learning basic," numerous people don't work in situations where they see it as protected to voice their opinions (Milliken, Morrison, and Hewlin, 2003). This poses an unsettling situation: Voice, which is characterized as the optional procurement of data expected to enhance authoritative working to somebody inside an association with the apparent power to act, despite the fact that such data might challenge and annoy usual business of the association and its stakeholders, is basic to hierarchical prosperity yet inadequately given by representatives, who see the dangers of employee voice as exceeding the advantages. In this manner, it is imperative to better comprehend who voices opinions with conceivably significant data and the hierarchical conditions that support or hinder such conduct.

Several studies indicate that employee voice is necessary for constructive organizational goals, such as performance (Detert \& Burris, 2007), extra-role conduct (Van Dyne \& LePine, 1998), invention (Zhou \& George, 2001), learning (Seibert, Kraimer, \& Crant, 2001), employee retention (Podsakoff et al., 2014), collective leadership (Carson, Tesluk, \& Marrone, 2007), and disaster avoidance and administration (Selart, Johansen, \& Nesse, 2013); nonetheless, many employees still view voice as a risk to their job security and mental welfare (Aryee, Walumbwa, Mondejar, \& Chu, 2014). Since voice includes recommendations to accomplish something in an unexpected way, pioneer practices flagging openness to or thankfulness for change ought to be a basic logical impact on worker ability to voice their opinions. Depictions from subjective examination recommend the significance of such practices. For instance, Edmondson (2003) documented that managers who expressly imparted a method of reasoning for change, clarified the requirement for others' info, and made a move on others' thoughts had followers who were additionally ready to add to group learning in spite of the innate dangers of voice behaviors. Here, we conjecture that two particular arrangements of observed pioneer practices-administration 
openness and transformational initiative-are especially demonstrative of an introduction toward persistent change and ought to thusly be absolutely identified with subordinates' conviction that it is protected to voice opinions and readiness to do as such.

\section{Significance and the scope of proposed study}

It is important to understand the various factors related to employee voice as it is an essential component in the improvement of organizational performance. The role of leadership in encouraging employees to express their voice is imperative as leadership possesses the power to enable employees to feel comfortable and reduce perceived issue threat. In an environment where employee participation is not hindered, more constructive suggestions are achievable. In the competitive business world of today, the top management alone is unable to improve organizational goals. Moreover, without the encouragement of employee voice, personnel are bound to feel unimportant and unheard. This could lead to a higher intent to quit on the part of employees. Hence, this study signifies intent to quit as an opposing outcome to voice behavior relating change-oriented leadership and the moderating and mediating factors to both the possible outcomes. In a way, this research describes two possible scenarios. In the case that changeoriented leadership is led by effective transformational leadership and managerial openness and employees feel reduced perceived issue threat and the employee personalities are suitable for positive voice behaviors. In such a setting employees are less likely to quit or see themselves working in a different organization. In the second scenario, change-oriented leadership is not open to employee voice and the employees perceive high level of issue threat and are more likely to quit. Employees with proactive personalities may feel themselves fitting into another organization that permits them to be more expressive and considers their inputs. Hence, this study contributes to a significant idea proposition by denoting that voice behavior can be an indicative of intent to quit with positive voice behaviors resulting in lesser intent to quit while negative voice behavior results in greater intent to quit.

\section{The proposed conceptual model}

Even though most of the factors that are included in this study have been examined in relation to one or another present variable in other studies, nonetheless, this research proposes a conceptual model that is complex. The primary association explored in this study is the effect of change-oriented leadership in terms of openness of management and transformational leadership on voice behaviors and intention to quit of the employees. This relationship has not been explored specifically in the past, however, transformational leadership has been examined with individual variables of 
intent to quit and voice behavior. The moderator and mediator further complicate this relationship. The main model for this study includes five components i.e., change-oriented leadership, employees' personality, perceived issue threat, intent to quit and voice behavior.

The moderator is selected to be employee personality. Although transformational leadership has also been found to have a positive effect on voice behaviors, change-oriented leadership in general is chosen which additionally include managerial openness and has been taken as the independent variable. The moderator is applied at the relationship between change-oriented leadership and perceived issue threat as leadership that is more inclined towards change and is open towards suggestions of the employees is likely to pose less threat while the employee personality decides the stance an employee chooses to take in an organizational setting. The dependent variables of intent to quit and voice behavior are affected by all of the other variables. In an environment where employees who have proactive personalities are free to speak up without perceived issue threat, they are more likely to want to stay with the organization and voice their opinions more.

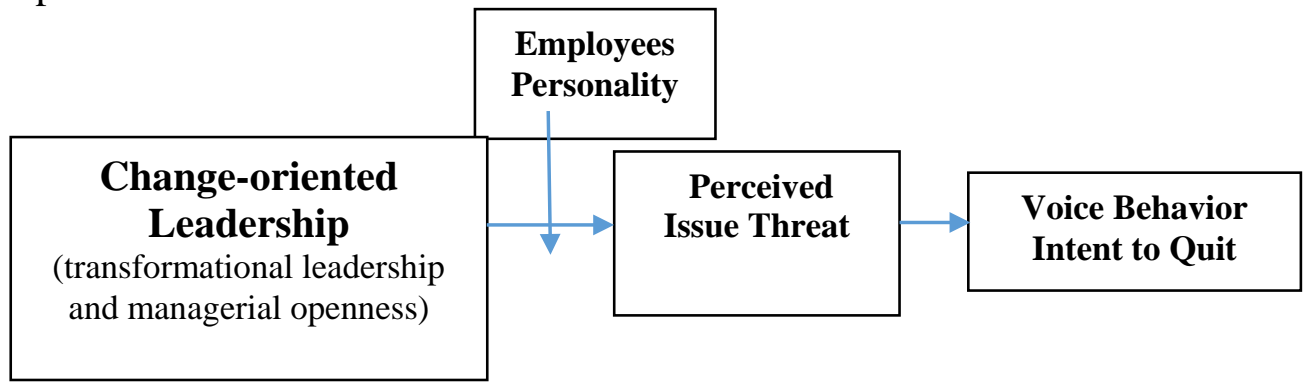

Figure 1: Conceptual Model

\section{Change-oriented leadership and outcomes}

Detert and Burris (2007) have observed the link between two kinds of change-based leadership and employee voice. These leadership styles are transformational leadership and openness of management. Their sample included 3,149 employees of a restaurant chain in addition to 223 managers. The results revealed that openness of management encourages voice. The limitations of this study are its inability to provide generalized results to be applied in various industries and how such openness is mediated by leadership forms.

\section{Managerial openness}

Research on issue offering (voice with respect to a particular work change or representative treatment point) has recognized managerial openness as an arrangement of leadership practices especially significant to 
employees' inspiration to voice their opinions (Ashford et al., 1998). Administrative openness alludes to subordinates' observations that their supervisor listens to their thoughts, is considerate of their opinions, gives reasonable thought to the opinions exhibited, and in any event, makes a move to address the matter pointed out. Such practices are important in keeping up beginning inspiration to employee voice (Milliken et al., 2003). All the more vitally, practices showing openness to representative information might diminish the remarkable quality of the force differential in the middle of pioneers and subordinates (Edmondson, 2003) in a manner that workers see few expenses from raising possibly threatening thoughts.

Similar to the top administration responsiveness idea proposed by House alongside Rizzo (1972), openness as identified with issue offering has been thought about essentially as a senior supervisor conduct. On the other hand, leaders show these practices to a more noteworthy or lesser degree at all various leveled stages. In this way, these practices likely impact upward interchanges by lower-level workers too. In reality, subjective exploration depicts administrative openness as a solid impact on workers at numerous hierarchical stages (Ryan and Oestrich, 1998).

Proposition 1: Managerial Openness is positively related to voice behavior and intent to quit.

\section{Transformational leadership}

Transformational leaders are the agents of organizational change. They possess the ability to inspire their followers to extend and raise their aims and increase their self-confidence. By their empowerment, the followers perform beyond the expected standards directed in their job agreements. Transformational leadership gathers individuals into a team and then motivates them to work towards a common goal. The main components of a transformational leadership are simulation on the intellectual level, motivation, idealized effect, and individual innovation (Bass, 1985) that could encourage voice behavior of employees. Liu, Zhu, and Yang (2010) have hypothesized voice to be sensitive to its targeted audience and classify voice behaviors into two dominant types in any workplace. The first type is speaking out to colleagues while the other is speaking up to managers. They proposed that transformational leadership supports both of these types of voice behaviors. Liu et al. (2010) conducted a survey consisting of 191 Chinese employees from various industries and companies. Results indicated that social identification anticipates voice behaviors while personal identification anticipates upward voice. The research exhibited how transformational leadership influences behavior of voice by promoting social and individual identification of employees. 
Several studies have connected transformational leadership and the moderating effect it has on the relationship between stressors and employee voice (Zhang et al., 2014; Cavanaugh et al., 2000; Zhang et al., 2015). While job satisfaction has also played a significant part in related research, employee turnover is also related to leadership styles. A more promoting and encouraging leadership style induces employees' trust in the management and motivates them to stay with the organization. While in cases where authoritative or rigid forms of leadership are applied when employees feel that they are unable to express themselves, a higher turnover is observed.

Transformational leaders are absolutely situated toward, and more inclined to start, change (Waldman, Javidan, and Varella, 2004). They perform change by urging representatives to move past consistency with formal understandings and to wind up creative issue solvers (Bass and Riggio, 2006). Various particular transformational practices, including individualized thought (Bass, 1985) and rousing inspiration ought to be identified with the voice equation. For instance, individualized thought mirrors the idea that every representative has particular qualities, intrigues, and requirements for development (Bass and Avolio, 1990) that must be taken care of one-on-one instead of by means of formal approaches or professions. Leaders showing individualized thought toward subordinates support two-way correspondence and listen adequately (Bass and Riggio, 2006). Likewise, leaders utilize moving inspiration to make responsibility among subordinates to their association's goals (Bass, 1985). Supervisors produce such duty by means of successive open correspondences about the imagined future bearing and objectives of the association and steady shows of energy about aggregate quest for the association's motivation (Conger, 1989).

Such practices of transformational leadership result in expanded subordinate skill and duty and additionally to strengthening and felt obligation to add to the future of the organization (Senge, 1990). For instance, instructing is prone to diminish the intimidation connected with raising uncomfortable points, for example, those testing existing conditions. Moreover, strong honing and vision sharing ought to increment beginning inspiration to talk up in light of the fact that they lead subordinates to acknowledge more aggregate obligation regarding execution results (Bennis and Nanus, 1985). These practices of transformational leadership ought to rouse subordinates to trust that their supervisors are arranged toward the future as opposed to safeguarding of the present state of affairs.

Proposition 2: Transformational leadership is positively related to voice behavior and intent to quit. 


\section{Perceived issue threat as a mediator}

Former examination on voice has concentrated transcendently on voicers' view of dangers to the self, giving careful consideration to voicers' impression of dangers to the assumed voice objectives, for example, to their supervisor. Ashford and associates (1998) observed that female directors were more averse to raise issues identified with ladies when they saw that raising such issues would hurt their picture in the association. Additionally, Detert alongside Edmondson (2011) found that representatives stayed quiet at work in view of socially gained convictions about components that made voice hazardous, for example, the conviction that talking up could have negative profession results. To be sure, much research on voice has summoned some sort of anticipation rationale to propose that when workers settle on choices about whether to talk up or stay quiet, they are especially worried about the potential dangers they might cause on themselves (Ajzen, 1991). In a research inspecting voice, Milliken and associates (2003) talked with 40 full-time representatives around if they felt they could straightforwardly express their worries and the purpose behind not raising their worries. They found that greater than $20 \%$ of the respondents referred to not having any desire to humiliate or hurt their managers as a noteworthy purpose behind staying quiet.

Issue threat alludes to representatives' observations that raising a thought might bring about hurt or misfortune to their voice beneficiaries' picture, notoriety, status, and believability in a voice event. Specifically, a few issues are especially additionally undermining to the substance of the director than different sorts of issues. Issues that representatives commonly raise incorporate the administrator's capability then again execution, issues with authoritative procedures, worries about pay and value, conflict with organization arrangements and choices, moral or reasonableness issues, badgering or mishandle, and strife with a collaborator (Milliken et al., 2003).

Proposition 3: Perceived issue threat is a mediating factor between the relationship of change-oriented leadership and voice behavior and intent to quit.

\section{Employee personality as a moderator}

The area of personality has been commanded for as far back as two decades by the five personality elements (Goldberg, 1990). The five elements generally named neuroticism (the inclination to experience negative influence, for example, and uneasiness, frailty and mental pain), extraversion (the amount and power of interpersonal cooperation and movement level), openness to encounter (the proactive looking for and energy about new encounters), suitability (the quality of one's interpersonal collaboration along a continuum from empathy to opposition), in addition to good faith (the 
measure of ingenuity, association and inspiration in objective coordinated practices) (Piedmont and Weinstein, 1994) have given scientists and experts with an unmistakable estimation structure and are dependable for the late resurgence of enthusiasm to identity inquire about and rehearse.

There is amassing proof that the recurrence of voice relies on upon an assortment of attitudes, such that even inside of the same work setting, a few people might show fundamentally more voice in comparison to others. As people are required to assign psychological assets to express their thoughts/sentiments interpersonally, in this examination, personality of employees was inspected to catch the impacts of individual properties on voice conduct. As of late, Fuller alongside Marler (2009) have recommended that employee personality is helpful for foreseeing singular conduct on the grounds that this attribute is moderately unconstrained by situational strengths and natural change. Therefore, employees who have proactive personalities have gotten much consideration for its hypothetical relevance to a few parts of proactive conduct (Parker et al., 2006), for example, hierarchical citizenship conduct and feedback seeking conduct. Workers with proactive personality are more likely to effectively look for answers for hierarchical issues, which may not be required in their formal obligations. In addition, Thompson (2005) suggests that they start valuable interpersonal contacts to give important data to different individuals from the association. In this manner, it is conceivable that employees with proactive personalities will talk up with their recommendations to start valuable changes for the advantage of their association. Fuller alongside Marler found that employees with proactive personalities are decidedly and essentially identified with voice conduct. Not at all like the Western connection in which they led their exploration, they found that Chinese employees are more likely to be more prepared to follow, instead of proactively talk up to, their pioneers in light of the more prominent force separation.

Proposition 4: Employee personality moderates the relationship between change-oriented leadership and perceived issue threat.

\section{Conclusion}

In conclusion of the above discussion, it can be proposed that changeoriented leadership led by managerial openness and transformational leadership has a positive impact on voice behavior and intent to quit. While change-oriented leadership encourages employee voice, it decreases the intent to quit of employees by providing them greater job satisfaction. The mediating effect of perceived issue threat indicates that change-oriented leadership creates an environment of safety for employees to freely express their opinions. In the time of crisis, employee voice can improve the organizational performance by suggesting innovative ideas. However, with a 
rigid kind of leadership, the employees could be too threatened by rejection. It could lead them to not expressing their ideas and hinder the organization's growth. Hence, transformational leadership is a precursor for positive voice behaviors. While in an environment where employees are not given room to express their ideas, and they desire a change to occur in the organization, such individuals are more likely to quit and find another organization that will provide them a more comfortable setting. Moreover, employee personality moderate the relationship between change oriented leadership and voice behavior and intent to quit. The employees that are proactive in a change-oriented leadership setting are likely to feel more accomplished by giving input in important managerial decision. Further studies should explore change-oriented behavior's impact in terms of diversity in promoting voice behaviors.

\section{References:}

Adams, J. S. (1965). Inequity in social exchange. Advances in experimental social psychology, 2(267-299).

Argote, L., \& Ingram, P. (2000). Knowledge transfer: A basis for competitive advantage in firms. Organizational behavior and human decision processes,82(1), 150-169.

Ashford, S. J., Rothbard, N. P., Piderit, S. K., \& Dutton, J. E. (1998). Out on a limb: The role of context and impression management in selling genderequity issues. Administrative Science Quarterly, 23-57.

Ashford, S. J., Sutcliffe, K. M., \& Christianson, M. K. (2009). Speaking up and speaking out: The leadership dynamics of voice in organizations. Voice and silence in organizations, 175-202.

Bandura, A. (1986). Social foundations of thought and action: A social cognitive theory. Prentice-Hall, Inc.

Bass, B. M., Avolio, B. J., \& Pointon, J. (1990). The implications of transactional and transformational leadership for individual, team, and organizational development.

Bass, B. M., \& Riggio, R. E. (2006). Transformational leadership. Psychology Press.

Bennis, W., \& Nanus, B. (1985). Organizational learning: the management of the collective self. New Management, 3(1), 6-13.

Bettencourt, L. A. (2004). Change-oriented organizational citizenship behaviors: the direct and moderating influence of goal orientation. Journal of Retailing,80(3), 165-180.

Burke, C. S., Stagl, K. C., Klein, C., Goodwin, G. F., Salas, E., \& Halpin, S. M. (2006). What type of leadership behaviors are functional in teams? A meta-analysis. The leadership quarterly, 17(3), 288-307. 
Burris, E. R., Detert, J. R., \& Chiaburu, D. S. (2008). Quitting before leaving: the mediating effects of psychological attachment and detachment on voice.Journal of Applied Psychology, 93(4), 912.

Conger, J. A. (1989). The charismatic leader: Behind the mystique of exceptional leadership. Jossey-Bass.

Detert, J. R., \& Burris, E. R. (2007). Leadership behavior and employee voice: Is the door really open?. Academy of Management Journal, 50(4), 869-884.

Detert, J. R., \& Edmondson, A. C. (2011). Implicit voice theories: Takenfor-granted rules of self-censorship at work. Academy of Management Journal,54(3), 461-488.

Detert, J. R., \& Trevino, L. K. (2010). Speaking up to higher-ups: How supervisors and skip-level leaders influence employee voice. Organization Science, 21(1), 249-270.

Dooley, R. S., \& Fryxell, G. E. (1999). Attaining decision quality and commitment from dissent: The moderating effects of loyalty and competence in strategic decision-making teams. Academy of Management journal, 42(4), 389-402.

Dutton, J. E., Ashford, S. J., Lawrence, K. A., \& Miner-Rubino, K. (2002). Red light, green light: Making sense of the organizational context for issue selling.Organization Science, 13(4), 355-369.

Dutton, J. E., Ashford, S. J., O'neill, R. M., Hayes, E., \& Wierba, E. E. (1997). Reading the wind: How middle managers assess the context for selling issues to top managers.

Edmondson, A. C. (2003). Speaking up in the operating room: How team leaders promote learning in interdisciplinary action teams. Journal of management studies, 40(6), 1419-1452.

Edmondson, A. C. (2003). Speaking up in the operating room: How team leaders promote learning in interdisciplinary action teams. Journal of management studies, 40(6), 1419-1452.

Fuller, B., \& Marler, L. E. (2009). Change driven by nature: A meta-analytic review of the proactive personality literature. Journal of Vocational Behavior,75(3), 329-345.

Grant, A. M., Gino, F., \& Hofmann, D. A. (2011). Reversing the extraverted leadership advantage: The role of employee proactivity. Academy of Management Journal, 54(3), 528-550.

Greenberg, J. (1990). Organizational justice: Yesterday, today, and tomorrow.Journal of management, 16(2), 399-432.

Choi, J. N. (2007). Change-oriented organizational citizenship behavior: Effects of work environment characteristics and intervening psychological processes.Journal of Organizational Behavior, 28(4), 467. 
House, R. J., \& Rizzo, J. R. (1972). Role conflict and ambiguity as critical variables in a model of organizational behavior. Organizational behavior and human performance, 7(3), 467-505.

Jaques, E., Clement, S. D., Rigby, C., \& Jacobs, T. O. (1986). Senior leadership performance requirements at the executive level. US Army Research Institute for the Behavioral and Social Sciences.

Kark, R., \& Carmeli, A. (2009). Alive and creating: The mediating role of vitality and aliveness in the relationship between psychological safety and creative work involvement. Journal of Organizational Behavior, 30(6), 785804.

Liang, J., Farh, C. I., \& Farh, J. L. (2012). Psychological antecedents of promotive and prohibitive voice: A two-wave examination. Academy of Management Journal, 55(1), 71-92.

MacKenzie, S. B., Podsakoff, P. M., \& Podsakoff, N. P. (2011). ChallengeOriented Organizational Citizenship Behaviors And Organizational Effectiveness: Do Challenge-Oriented Behaviors Really Have An Impact On The Organization's Bottom Line?. Personnel Psychology, 64(3), 559-592.

Milliken, F. J., Morrison, E. W., \& Hewlin, P. F. (2003). An exploratory study of employee silence: Issues that employees don't communicate upward and why*.Journal of management studies, 40(6), 1453-1476.

Morrison, E. W., \& Milliken, F. J. (2000). Organizational silence: A barrier to change and development in a pluralistic world. The Academy of Management Review, 25(4), 706-725.

Nemeth, C. J. (1997). Managing innovation: When less is more. California Management Review, 40, 59-74.

Ryan, K. D., \& Oestrich, D. K. (1998). Driving fear out of the workspace.

Schein, E. H. (1992). How can organizations learn faster?: the problem of entering the Green Room. Alfred P. Sloan School of Management, Massachusetts Institute of Technology.

Tangirala, S., Kamdar, D., Venkataramani, V., \& Parke, M. R. (2013). Doing right versus getting ahead: The effects of duty and achievement orientations on employees' voice. Journal of Applied Psychology, 98(6), 1040.

Trice, H. M., \& Beyer, J. M. (1993). The cultures of work organizations. Prentice-Hall, Inc.

Waldman, D. A., Javidan, M., \& Varella, P. (2004). Charismatic leadership at the strategic level: A new application of upper echelons theory. The Leadership Quarterly, 15(3), 355-380.

Withey, M. J., \& Cooper, W. H. (1989). Predicting exit, voice, loyalty, and neglect. Administrative Science Quarterly, 521-539. 